VILLAS BÔAS, R.L.; PASSOS, J.C.; FERNANDES, M.; BÜLL, L.T.; CEZAR, V.R.S.; GOTO, R. Efeito de doses e tipos de compostos orgânicos na produção de alface em dois solos sob ambiente protegido. Horticultura Brasileira, Brasília, v.22, n.1, p.28-34, jan-mar 2004.

\title{
Efeito de doses e tipos de compostos orgânicos na produção de alface em dois solos sob ambiente protegido
}

\author{
Roberto L. Villas Bôas; Júlio Cesar Passos; Dirceu Maximino Fernandes; Leonardo Theodoro Büll; \\ Vicente Rodolfo S. Cezar; Rumy Goto \\ UNESP, FCA, C. Postal 237, 18603-970 Botucatu-SP; E-mail: rlvboas@fca.unesp.br
}

\section{RESUMO}

Avaliou-se o efeito de três doses de composto orgânico de três composições distintas, aplicados em dois solos [Latossolo Vermelho Escuro, textura arenosa (LE) e Areia Quartzoza (AQ)], na produção e absorção de nutrientes pela planta de alface. Conduziu-se de 02/07 a 27/08/1997 um experimento dentro de túnel plástico, pertencente à UNESP, em Botucatu, em vaso plástico, contendo quatro quilos de solo. Os solos foram corrigidos para atingirem saturação por base de $80 \%$ e todos os vasos receberam adubação fosfatada (150 mg de $\mathrm{P} \mathrm{kg}^{-1}$ de solo), potássica (100 $\mathrm{mg} \mathrm{de} \mathrm{K} \mathrm{kg}^{-1} \mathrm{de}$ solo) e micronutrientes. Os compostos foram misturados aos solos nas quantidades de $60 ; 120$ e $240 \mathrm{~g}$ de composto por vaso. Os três compostos foram originados a partir de casca de eucalipto, serragem de madeira e palhada de feijão, misturados com esterco de aves. $\mathrm{O}$ experimento foi realizado em delineamento inteiramente casualizado, em três repetições, com vinte tratamentos em esquema fatorial ( 3 doses $\mathrm{x} 3$ compostos $\mathrm{x} 2$ solos) mais um tratamento testemunha para cada solo (ausência de composto orgânico). O composto de palhada de feijão aumentou a biomassa fresca da parte aérea $\mathrm{e}$ a quantidade de $\mathrm{N}, \mathrm{K}, \mathrm{Ca}, \mathrm{Mg}, \mathrm{B}, \mathrm{Cu}, \mathrm{Fe}$ e $\mathrm{Zn}$ nas plantas de alface. Para o $\mathrm{P}$ e Mn o composto de palhada de feijão diferiu significativamente apenas em relação ao composto de casca de eucalipto. Em todas as características avaliadas no LE houve melhores respostas da cultura em relação ao AQ. Quanto às dosagens utilizadas, as diferenças foram observadas somente nos tratamentos com palhada de feijão, onde as maiores dosagens propiciaram o aumento de biomassa fresca e seca da parte aérea, e nas quantidades de macro e micronutrientes.

Palavras-chave: Lactuca sativa L., fertilizante orgânico, nutrição, extração de nutrientes.

\section{ABSTRACT}

Effects of dosage and types of organic composts in the production of lettuce in two soils under protected environment

The effects of three doses of organic composts of three different origins, applied to two soil types, were evaluated on production and absorption of nutrients by lettuce. The experiment was conducted under plastic tunnel, at the Faculdade de Ciências Agronômicas, in Botucatu, Brazil, in plastic vase each with 4 liters of soil. The soils [Oxisol (Dark Red Latosoil) (LE), sandy phase, and an Inceptisol (AQ)] were corrected to reach $80 \%$ of base saturation and all the vases received $150 \mathrm{mg} \cdot \mathrm{kg}^{-1}$ of $\mathrm{P}, 100 \mathrm{mg} \cdot \mathrm{kg}^{-1}$ of $\mathrm{K}$ and micronutrients. The composts were mixed to the soils in amounts of $60 ; 120$ and $240 \mathrm{~g} \mathrm{vase}^{-1}$. The composts, originated from a mixture of eucalyptus bark, wood sawdust and bean straw, were mixed with chicken manure. The experiment was accomplished following a randomized design, with 18 treatments and 3 replicates ( 3 doses $\times 2$ soils $x 3$ composts) plus a control. The bean straw compost increased the fresh weight of the aerial part and the amount of $\mathrm{N}, \mathrm{K}, \mathrm{Ca}, \mathrm{Mg}, \mathrm{B}, \mathrm{Cu}, \mathrm{Fe}$ and $\mathrm{Zn}$ in the lettuce plants, but differed for $\mathrm{P}$ and $\mathrm{Mn}$ only in relation to eucalyptus bark compost. In all the characteristics evaluated in the LE the best results were obtained in relation to AQ. Larger doses of bean straw promoted increase in fresh weight of aerial part, and in the amount of $\mathrm{N}, \mathrm{K}, \mathrm{Ca}, \mathrm{Mg}, \mathrm{S}, \mathrm{Fe}$ and $\mathrm{Zn}$.

Keywords: Lactuca sativa L., mineral nutrition, organic fertilizer.

(Recebido para publicação em 7 de agosto de 2002 e aceito em 15 de dezembro de 2003)

\begin{abstract}
$\mathrm{A}$ alface, desde sua domesticação a partir de espécies silvestres, tornouse a principal folhosa consumida pelo homem, tendo sido comercializados pela CEAGESP 14.101 toneladas em 1999 (FNP Consultoria e Comércio, 2000).

É a hortaliça tradicionalmente cultivada por pequenos produtores, o que lhe confere grande importância econômica e social, sendo significativo fator de agregação do homem do campo. Aliado a isso, a grande necessidade de adubação orgânica da cultura (Nakagawa et $a l .$, 1993), faz dessa hortaliça um importante componente no enfoque holístico da agricultura orgânica.
\end{abstract}

As fontes de adubos orgânicos podem apresentar características bastante distintas, podendo ser agrupados em fertilizante orgânico e fertilizante composto. O fertilizante orgânico é o "fertilizante de origem vegetal ou animal contendo um ou mais nutrientes das plantas" e o fertilizante composto ou simplesmente composto é o "fertilizante obtido por processo bioquímico, natural ou controlado com mistura de resíduos de origem vegetal ou animal". As terminologias utilizadas neste texto seguirão essas definições.

A adubação orgânica tem grande importância no cultivo de hortaliças, principalmente em solos de clima tropical, onde a queima de matéria orgânica se realiza intensamente, e onde seu efeito é bastante conhecido nas propriedades físicas, químicas e biológicas do solo (Allison, 1973; Senesi, 1989; Swift e Woomer, 1993).

A grande maioria dos trabalhos encontrados na literatura diz respeito ao uso de estercos, resíduos líquidos e restos vegetais, reportando seu efeito como melhoradores do solo e fornecedores de nutrientes. Embora parte dessa informação possa ser extrapolada e assumida como válida no que diz respeito ao uso de compostos, estes têm uma dinâmica 
no solo bastante diversa dos materiais em estado cru, por ser uma matéria orgânica decomposta e estabilizada (Kiehl, 1985).

As condições fisiológicas inerentes à alface, tais como a eficiência de utilização de nitrogênio sempre menor que 50\% (Alexander, 1965) e a absorção de aproximadamente $80 \%$ de $\mathrm{N}$ total extraído nas últimas quatro semanas do ciclo (Katayama, 1993), explicam o interesse no uso de fertilizantes de solubilização lenta (Pereira et al., 1989). Nesse sentido o adubo orgânico adicionado ao solo tem efeito imediato e ainda residual por meio de um processo mais lento de decomposição e liberação de nutrientes. Além disso, a matéria orgânica melhora as condições químicas, físicas e biológicas do solo, o que reforça o interesse de sua utilização como fonte de nitrogênio para a cultura da alface (Vidigal et al., 1995).

As características do composto orgânico podem ter significado importante na estabilização do húmus ou adubo orgânico formado (Peixoto, 2000). Um composto estabilizado deverá ter a relação $\mathrm{C} / \mathrm{N}$ igual ou menor que 18. Entretanto, se o composto apresentar relação $\mathrm{C} / \mathrm{N}$ acima de 30 , os microorganismos irão utilizar o nitrogênio do solo competindo com as plantas. Isto ocorre com resíduos ricos em celulose, que necessitam de grande população de microorganismos específicos para a decomposição (Kiehl,1998).

As recomendações de doses variam com o tipo de composto orgânico aplicado, com o solo, a cultura e as condições ambientais. Em geral, as taxas de aplicação estão entre 10 a $100 \mathrm{t} \mathrm{ha}^{-1}$, porém níveis mais elevados não são incomuns. Aumentos lineares no peso de "cabeça" de alface foram obtidos com doses de até $10,8 \mathrm{~kg} \mathrm{~m}^{-2}$ de esterco de curral, além de propiciar incrementos nos teores de nitrogênio e fósforo das plantas (Schneider, 1983).

Com relação ao tipo de adubo orgânico, Ricci et al. (1994) obtiveram maior produtividade para aplicação de $10 \mathrm{tha}^{-1}$ de húmus de minhoca em relação à mesma quantidade do composto orgânico. Koga e Seno (1997) observaram que composto orgânico de casca de eucalipto + esterco de galinha proporcionou maior produção total e comercial de plantas de alface e pepino em relação ao de bagaço de cana e de casca de amendoim misturada a esterco de galinha. Apesar do uso de adubo orgânico no solo ser uma prática bastante antiga, existe pouca informação sobre os efeitos no rendimento e qualidade da alface quando submetida à aplicação de diferentes compostos orgânicos (Ricci et al., 1994) ou a diferentes tipos de solo.

Considerando que a alface é adubada com quantidades elevadas de fertilizantes, principalmente nitrogenados, desenvolveu-se este trabalho com objetivo de avaliar o efeito de tipos (em relação ao material de origem) e doses de diferentes compostos orgânicos, em dois solos, sobre a nutrição e produção de alface em ambiente protegido.

\section{MATERIAL E MÉTODOS}

O experimento foi conduzido de $02 /$ 07 a 27/08/1997 em ambiente protegido com estrutura metálica coberta com polietileno, pertencente à UNESP em Botucatu. Os solos utilizados foram Latossolo Vermelho Escuro textura arenosa (LE) e Areia Quartzoza (AQ). A análise química do (LE) indicou: $\mathrm{pH}$ em $\mathrm{CaCl}_{2}=4,0 ;$ M.O. $=23 \mathrm{~g} \mathrm{dm}^{-3} ; \mathrm{P}$ resina $=2$ $\mathrm{g} \mathrm{dm}^{-3} ; \mathrm{H}^{+}+\mathrm{Al}^{3+}=72 \mathrm{mmol}_{\mathrm{c}} \mathrm{dm}^{-3} ; \mathrm{K}^{+}=0,5$ $\mathrm{mmol}_{\mathrm{c}} \mathrm{dm}^{-3} ; \mathrm{Ca}^{2+}=1 \mathrm{mmol}_{\mathrm{c}} \mathrm{dm}^{-3} ; \mathrm{Mg}^{2+}=1$ $\mathrm{mmol}_{\mathrm{c}} \mathrm{dm}^{-3} ; \mathrm{SB}=2,5 \mathrm{mmol}_{\mathrm{c}} \mathrm{dm}^{-3} ; \mathrm{CTC}=$ $74 \mathrm{mmol}_{\mathrm{c}} \mathrm{dm}^{-3}$ e $\mathrm{V} \%=3$. Para o (AQ) as características químicas foram $\mathrm{pH}$, em $\mathrm{CaCl}_{2}=4,7 ; \mathrm{M} . \mathrm{O} .=8 \mathrm{~g} \mathrm{dm}^{-3} ; \mathrm{P}$ resina $=3 \mathrm{~g}$ $\mathrm{dm}^{-3} ; \mathrm{H}^{+}+\mathrm{Al}^{3+}=14 \mathrm{mmol} \mathrm{dm}_{\mathrm{c}}^{-3} ; \mathrm{K}^{+}=0,6$ $\mathrm{mmol}_{\mathrm{c}} \mathrm{dm}^{-3} ; \mathrm{Ca}^{2+}=5 \mathrm{mmol}_{\mathrm{c}} \mathrm{dm}^{-3} ; \mathrm{Mg}^{2+}=2$ $\mathrm{mmol}_{\mathrm{c}} \mathrm{dm}^{-3} ; \mathrm{SB}=7,6 \mathrm{mmol}_{\mathrm{c}} \mathrm{dm}^{-3} ; \mathrm{CTC}=$ $22 \mathrm{mmol}_{\mathrm{c}} \mathrm{dm}^{-3}$ e V\%=36.

Os solos foram corrigidos de modo a atingirem a saturação por bases de $80 \%$, segundo recomendação de Raij et al. (1997). Como adubação básica todos os tratamentos receberam $150 \mathrm{mg}$ de $\mathrm{P} \mathrm{kg}^{-1}$ de solo (superfosfato triplo), $100 \mathrm{mg}$ de $\mathrm{K} \mathrm{kg}^{-1}$ de solo (cloreto de potássio) e $1 \mathrm{~g}$ de FTE-BR-8 por vaso (7\% Zn; 2,5\% B; $1 \% \mathrm{Cu} ; 5 \%$ Fe; $10 \%$ Mn e $0,1 \%$ Mo).

Os materiais utilizados na compostagem foram casca de eucalipto, serragem de madeira e palhada de feijão, sendo cada um misturado ao esterco de galinha. A casca de eucalipto foi obtida junto à DURATEX S/A; a serragem, mistura de pó e maravalha proveniente de cerne de madeira de lei, obtida junto à madeireira MURBA Ltda.; e a palhada de feijão, resíduo da operação de beneficiamento das plantas com trilhadeira estacionário, foi coletada junto à FCA/UNESP. A proporção das misturas, palhas/esterco, foi tal que se aproximou da relação de 30/1 antes da compostagem, conforme sugerido por Kiehl (1985).

Após a compostagem, as análises químicas dos compostos orgânicos, segundo Lanarv (1988), revelaram (em $\mathrm{gkg}^{-1}$ ): Composto orgânico 1 (mistura de esterco de aves + casca de eucalipto) $\mathrm{N}$ $(12,8)$; $\mathrm{P}_{2} \mathrm{O}_{5}(12,2)$; $\mathrm{K}_{2} \mathrm{O}(8,0)$; M.O. $(534,6) ; \mathrm{C}(304,2) ; \mathrm{Ca}^{2+}(22,9) ; \mathrm{Mg}^{2+}$ $(2,0)$; $\mathrm{S}(2,4) ; \mathrm{pH}$ em $\mathrm{CaCl}_{2}(8,1)$ e relação C/N (23/1). Composto orgânico 2 (mistura de esterco de aves + serragem de madeira) $\mathrm{N}(9,4) ; \mathrm{P}_{2} \mathrm{O}_{5}(16,5) ; \mathrm{K}_{2} \mathrm{O}$ (1,5); M.O. (429,3); C $(239,3)$; $\mathrm{Ca}^{2+}$ $(26,2) ; \mathrm{Mg}^{2+}(1,9) ; \mathrm{S}(1,7) ; \mathrm{pH}$ em $\mathrm{CaCl}_{2}$ $(7,1)$ e relação $\mathrm{C} / \mathrm{N}(26 / 1)$. Composto orgânico 3 (mistura de esterco de aves + palhada de feijão) $\mathrm{N}(21,5) ; \mathrm{P}_{2} \mathrm{O}_{5}(9,2)$; $\mathrm{K}_{2} \mathrm{O}(5,8)$; M.O. (395,6); C $(219,8) ; \mathrm{Ca}^{2+}$ $(8,1) ; \mathrm{Mg}^{2+}(4,3) ; \mathrm{S}(3,4) ; \mathrm{pH}$ em $\mathrm{CaCl}_{2}$ $(7,0)$ e relação C/N (10/1).

Os compostos foram secos em estufa $\left(60^{\circ} \mathrm{C}\right)$, passados em peneira de malha 4 mm e misturados aos solos em quantidades equivalentes a 1,$5 ; 3,0$ e $6,0 \%$, com base em massa, o que correspondeu às quantidades de 60, 120 e 240 gramas de cada composto seco, por vaso de quatro quilos de capacidade.

O experimento foi realizado em delineamento inteiramente casualizado, em três repetições, com vinte tratamentos em esquema fatorial ( 3 doses $\mathrm{x} 3$ compostos $\mathrm{x} 2$ solos) mais uma testemunha para cada solo (ausência de composto orgânico), totalizando 60 vasos.

Utilizou-se a cultivar Elisa, cujas mudas foram produzidas em bandejas de poliestireno expandido, utilizando-se substrato comercial. Durante o ciclo da cultura foram avaliados o número de folhas (usou-se como referência o tamanho, sendo contadas somente folhas maiores que $4 \mathrm{~cm}$ ) e a medida indireta de clorofila (com medidor portátil de clorofila da marca SPAD-502, apresentando os resultados em unidades 
Tabela 1. Características avaliadas em plantas de alface cultivar Elisa na colheita, aos 56 dias após o transplante das mudas. Botucatu, UNESP, 1997.

\begin{tabular}{|c|c|c|c|c|c|c|}
\hline $\begin{array}{l}\text { Tipo de } \\
\text { composto } \\
\text { orgânico }\end{array}$ & $\begin{array}{l}\text { Doses } \\
\left(\text { g vaso-1) }^{-1}\right)\end{array}$ & $\begin{array}{l}\text { Biomassa } \\
\text { fresca } \\
\left(\text { g planta }^{-1}\right)\end{array}$ & $\begin{array}{l}\text { Biomassa } \\
\text { fresca }^{1} \\
\left(\text { g planta-1 }^{-1}\right)\end{array}$ & $\begin{array}{c}\text { Biomasaseca } \\
\left(\text { g planta }^{-1}\right)\end{array}$ & No de folhas & $\begin{array}{l}\text { Unidades } \\
\text { SPAD } \\
\text { clorofila }^{2}\end{array}$ \\
\hline & & \multicolumn{5}{|c|}{ Tipo de composto $\mathrm{x}$ doses } \\
\hline \multirow{3}{*}{$\begin{array}{l}\text { Casca de } \\
\text { eucalip to }\end{array}$} & 60 & $97,7 a$ & $83,5 \mathrm{a}$ & $9,1 \mathrm{a}$ & $30 a$ & $20,7 \mathrm{a}$ \\
\hline & 120 & 93,8 a & $80,1 \mathrm{a}$ & $8,0 \mathrm{a}$ & $31 a$ & $19,6 a$ \\
\hline & 240 & $88,5 \mathrm{a}$ & $74,3 \mathrm{a}$ & $7,5 \mathrm{a}$ & $30 a$ & $19,1 \mathrm{a}$ \\
\hline Média & & $93,3 \mathrm{~B}$ & $79,3 \mathrm{~B}$ & $8,2 \mathrm{~B}$ & $30 \mathrm{~B}$ & $19,8 \mathrm{~B}$ \\
\hline \multirow{3}{*}{$\begin{array}{l}\text { Serragem de } \\
\text { madeira }\end{array}$} & 60 & 99,2 a & $85,0 a$ & $9,4 a$ & $30 a$ & $20,8 a$ \\
\hline & 120 & 97,8 a & $84,4 \mathrm{a}$ & $9,0 \mathrm{a}$ & $30 a$ & $19,0 \mathrm{a}$ \\
\hline & 240 & 95,6 a & $82,2 a$ & $8,9 a$ & $29 a$ & $21,7 \mathrm{a}$ \\
\hline Média & & $97,5 \mathrm{~B}$ & $83,9 \mathrm{~B}$ & $9,1 \mathrm{AB}$ & $30 \mathrm{~B}$ & $20,5 \mathrm{AB}$ \\
\hline \multirow{3}{*}{$\begin{array}{l}\text { Palhada de } \\
\text { feijão }\end{array}$} & 60 & $110,6 \mathrm{~b}$ & $94,7 \mathrm{~b}$ & $9,0 \mathrm{~b}$ & $31 \mathrm{~b}$ & $20,4 \mathrm{a}$ \\
\hline & 120 & $132,1 \mathrm{~b}$ & $113,2 b$ & $9,4 \mathrm{~b}$ & $33 \mathrm{~b}$ & $21,5 a$ \\
\hline & 240 & $193,9 a$ & $168,1 \mathrm{a}$ & $13,4 \mathrm{a}$ & $37 a$ & $23,0 \mathrm{a}$ \\
\hline \multirow[t]{2}{*}{ Média } & & $145,5 \mathrm{~A}$ & $125,3 \mathrm{~A}$ & $10,6 \mathrm{~A}$ & $33 \mathrm{~A}$ & $21,6 \mathrm{~A}$ \\
\hline & & & & Solo & & \\
\hline LE & & $140,2 \mathrm{a}$ & $120,8 \mathrm{a}$ & $10,6 a$ & $35 \mathrm{a}$ & $21,9 a$ \\
\hline \multirow[t]{2}{*}{$\mathrm{AQ}$} & & $84,1 \mathrm{~b}$ & $71,5 \mathrm{~b}$ & $8,0 \mathrm{~b}$ & $28 \mathrm{~b}$ & $19,6 \mathrm{~b}$ \\
\hline & & & & Testemunha & & \\
\hline$\overline{\mathrm{LE}}$ & & 118,4 & 100,5 & 9,4 & 32 & 23,2 \\
\hline$A Q$ & & 74,6 & 63,6 & 8,4 & 27 & 18,7 \\
\hline Média & & 96,5 & 82,1 & 8,9 & 29 & 20,9 \\
\hline$\overline{\mathrm{CV}}(\%)$ & & 25 & 25 & 21 & 12 & 8 \\
\hline
\end{tabular}

${ }^{1}$ Biomassa fresca após 24 horas conservada em laboratório a $\mathrm{T}$ ambiente (média de $15^{\circ} \mathrm{C}$ ). ${ }^{2}$ Unidades dadas pelo aparelho marca Minolta, modelo SPAD 502.

Letras minúsculas comparam médias das doses dentro de cada composto e médias de solos. Letras maiúsculas comparam médias entre os compostos. Médias seguidas das mesmas letras não diferem estatisticamente entre si pelo teste de Tukey à 5\% de probabilidade.

SPAD.), semanalmente e, ao final do ciclo das plantas, antes da colheita, foram realizadas determinações do número de folhas e do teor de clorofila.

As plantas foram colhidas 56 dias após o transplante, determinada a biomassa fresca e em seguida, colocadas em laboratório à temperatura ambiente (média de $15^{\circ} \mathrm{C}$ ), sobre uma bancada, onde permaneceram por 24 horas. A seguir foi determinada novamente a biomassa, sendo as plantas posteriormente colocadas a secar em estufa de circulação de ar forçada a $65^{\circ} \mathrm{C}$, até massa constante. $\mathrm{O}$ material foi moído e analisado quimicamente quanto aos teores de macro e micronutrientes, seguindo metodologia citada por Malavolta et al. (1997).

As análises estatísticas foram executadas por meio de programa de com- putador Estat, conforme método descrito por Banzato e Kronka (1989).

\section{RESULTADOS E DISCUSSÃO}

Para biomassa fresca (Tabela 1) houve efeito distinto em função do tipo de composto. Para os compostos obtidos a partir de casca de eucalipto e de serragem de madeira, não houve diferenças entre as dosagens e as plantas mantiveram massas semelhantes às obtidas na testemunha. No entanto, para o composto com palhada de feijão, a dose mais elevada promoveu resultado estatisticamente superior, duplicando a biomassa fresca da alface em relação à testemunha. Pode-se considerar portanto que não ocorreu resposta para doses de compostos orgânicos provenientes de casca de eucalipto e serragem de madeira, porém para palhada de feijão a alface respondeu de forma crescente até $240 \mathrm{~g}$ do composto por vaso. A biomassa fresca obtida no tratamento com $240 \mathrm{~g}$ vaso $^{-1}$ de composto proveniente de palhada de feijão foi de $194 \mathrm{~g} /$ planta, quando considerada a média dos dois solos, porém chegou a 241 gramas no LE. Por essa e outras diferenças observadas, a biomassa fresca da planta de alface foi estatisticamente superior no LE em relação ao AQ. Vidigal et al. (1997), avaliando o efeito de diferentes compostos orgânicos, atribuíram as menores produtividades de alface, cv. Carolina, a compostos orgânicos que não haviam mineralizado o suficiente para nutrir as plantas, como por exemplo o bagaço de cana-de-açúcar, quando comparado à palha de café. Juang e Chang (1992) 
Efeito de doses e tipos de compostos orgânicos na produção de alface em dois solos sob ambiente protegido

Tabela 2. Quantidade de macronutrientes em plantas de alface cultivar Elisa na colheita, aos 56 dias após transplante. Botucatu, UNESP, 1997.

\begin{tabular}{|c|c|c|c|c|c|c|c|}
\hline \multirow{2}{*}{$\begin{array}{l}\text { Tipo de } \\
\text { composto } \\
\text { orgânico }\end{array}$} & \multirow{2}{*}{$\begin{array}{l}\text { Doses em } \\
\left(\text { g vaso- }^{-1}\right)\end{array}$} & \multicolumn{6}{|c|}{ Quantidade (mg planta-1) } \\
\hline & & $\mathbf{N}$ & $\mathbf{P}$ & K & $\mathrm{Ca}$ & Mg & $\mathbf{S}$ \\
\hline & & \multicolumn{6}{|c|}{ Tipo de composto $x$ doses } \\
\hline \multirow{3}{*}{$\begin{array}{l}\text { Casca de } \\
\text { eucalipto }\end{array}$} & 60 & 156 aA & $23 a$ & 376 aA & 79 aA & 29 aA & 9 aA \\
\hline & 120 & $143 \mathrm{aB}$ & 22 a & $363 \mathrm{aB}$ & $74 \mathrm{aA}$ & $25 \mathrm{aB}$ & $8 \mathrm{aB}$ \\
\hline & 240 & $133 \mathrm{aB}$ & $24 a$ & $347 \mathrm{aB}$ & $57 \mathrm{aB}$ & $22 \mathrm{aB}$ & $8 \mathrm{aB}$ \\
\hline Média & & $144 \mathrm{~B}$ & $23 \mathrm{~B}$ & $362 \mathrm{~B}$ & $70 \mathrm{~B}$ & $25 \mathrm{~B}$ & $8 \mathrm{~B}$ \\
\hline \multirow{3}{*}{$\begin{array}{l}\text { Serragem } \\
\text { de madeira }\end{array}$} & 60 & $151 \mathrm{aA}$ & $25 a$ & 359 aA & 72 aA & 29 aA & $8 \mathrm{aA}$ \\
\hline & 120 & $143 \mathrm{aB}$ & $27 a$ & $370 \mathrm{aB}$ & 74 aA & $26 \mathrm{aB}$ & $8 \mathrm{aB}$ \\
\hline & 240 & $152 \mathrm{aB}$ & 29 a & $400 \mathrm{aB}$ & $68 \mathrm{aB}$ & $27 \mathrm{aA}$ & $8 \mathrm{aB}$ \\
\hline Média & & $149 \mathrm{~B}$ & $27 \mathrm{AB}$ & $376 \mathrm{~B}$ & $72 \mathrm{~B}$ & $27 \mathrm{~B}$ & $8 \mathrm{~B}$ \\
\hline \multirow{3}{*}{$\begin{array}{l}\text { Palhada de } \\
\text { feijão }\end{array}$} & 60 & $182 \mathrm{bA}$ & $26 \mathrm{~b}$ & $419 \mathrm{bA}$ & $80 \mathrm{bA}$ & $32 \mathrm{bA}$ & $11 \mathrm{bA}$ \\
\hline & 120 & 208 bA & $30 \mathrm{~b}$ & 556 bA & $85 \mathrm{bA}$ & $37 \mathrm{bA}$ & $14 \mathrm{bA}$ \\
\hline & 240 & $361 \mathrm{aA}$ & $41 a$ & $931 \mathrm{aA}$ & 114 aA & $54 \mathrm{aA}$ & 24 aA \\
\hline \multirow[t]{2}{*}{ Média } & & $250 \mathrm{~A}$ & $32 \mathrm{~A}$ & $636 \mathrm{~A}$ & $93 \mathrm{~A}$ & $41 \mathrm{~A}$ & $17 \mathrm{~A}$ \\
\hline & & \multicolumn{6}{|c|}{ Solo } \\
\hline$\overline{\mathrm{LE}}$ & & $242 a$ & 29 a & $574 a$ & $91 \mathrm{a}$ & $40 \mathrm{a}$ & $14 \mathrm{a}$ \\
\hline \multirow[t]{2}{*}{$A Q$} & & $121 \mathrm{~b}$ & $26 a$ & $341 \mathrm{~b}$ & $65 \mathrm{a}$ & $22 \mathrm{~b}$ & $7 \mathrm{~b}$ \\
\hline & & \multicolumn{6}{|c|}{ Testemunha } \\
\hline$\overline{\mathrm{LE}}$ & & 195 & 20 & 354 & 78 & 38 & 11 \\
\hline$A Q$ & & 112 & 23 & 267 & 55 & 23 & 6 \\
\hline Média & & 153 & 21 & 310 & 66 & 30 & 8 \\
\hline$\overline{\mathrm{CV}(\%)}$ & & 24 & 29 & 25 & 21 & 26 & 27 \\
\hline
\end{tabular}

Letras minúsculas comparam médias das doses dentro de cada composto e médias de solos. Letras maiúsculas comparam médias entre os compostos para uma mesma dose. Médias seguidas das mesmas letras não diferem estatisticamente entre si pelo teste de Tukey à $5 \%$ de probabilidade.

obtiveram resultados semelhantes para cultura de arroz e milho. No entanto, Nakagawa et al. (1992) cultivando alface Brasil-48, concluíram que a utilização de $150 \mathrm{~g}$ de composto orgânico de diferentes resíduos agrícolas não produziu diferença significativa para biomassa fresca de folhas e caules.

Para biomassa fresca, determinada um dia após a colheita, observou-se resultados semelhantes aos discutidos anteriormente, sendo que a perda de água das plantas foi em média de $14,5 \%$ para os três tipos de compostos, sugerindo que os tratamentos não influenciaram a desidratação das plantas, um dia após a colheita.

Para a biomassa seca foram observadas diferenças significativas entre as doses apenas para o composto de palhada de feijão. Este apresentou resultados superiores ao de casca de eucalipto. Houve também diferença significativa entre os solos, sendo os valores médios de biomassa seca da planta de alface de 10,6 e 8,0 g, respectivamente para o LE e AQ. Nota-se que tanto o composto de casca de eucalipto quanto o de serragem não influenciaram a biomassa seca de alface e, os resultados obtidos foram semelhantes ao encontrado na testemunha ( $8,9 \mathrm{~g}$ por planta), sugerindo que esses dois compostos não disponibilizaram nutrientes para o desenvolvimento da parte aérea da planta.

O número de folhas determinado semanalmente, somente apresentou diferença entre tratamentos nas avaliações realizadas aos 49 e 56 dias após o transplante (dat). Na Tabela 1 são apresentados somente os resultados obtidos na colheita (56 dat), pois aos 49 dat, as médias dos tratamentos apresentaram as mesmas diferenças ocorridas aos 56 dat.
O número de folhas da alface variou com as doses apenas no emprego do composto de palhada de feijão, sendo encontrado maior número de folhas com a aplicação de $240 \mathrm{~g}$ vaso $^{-1} \mathrm{e}$, entre os solos, no LE. As diferenças observadas aos 56 dat coincidem com o período de máxima demanda de nutrientes pela planta de alface (Garcia et al. 1982), que ocorre nas últimas semanas do ciclo. Esse aspecto reforça a idéia de que o composto obtido de palhada de feijão disponibilizou mais nutrientes, o que não ocorreu para os demais compostos.

A medida indireta da clorofila (unidade SPAD), determinada através do clorofilômetro nas folhas de alface, mostrou diferença significativa entre os tipos de compostos orgânicos, sendo que o de casca de eucalipto proporcionou menor valor em relação à palhada de feijão e, ambos, não diferiram da serra- 
Tabela 3. Quantidade de micronutrientes em plantas de alface cultivar Elisa na colheita, aos 56 dias após o transplante. Botucatu, UNESP, 1997.

\begin{tabular}{|c|c|c|c|c|c|c|}
\hline \multirow{2}{*}{$\begin{array}{c}\text { Tipos de } \\
\text { compostos } \\
\text { orgânicos }\end{array}$} & \multirow{2}{*}{$\begin{array}{l}\text { Doses } \\
\left(\text { g vaso-1) }^{-1}\right)\end{array}$} & \multicolumn{5}{|c|}{ Quantidade em mg planta-1 } \\
\hline & & B & $\mathrm{Cu}$ & $\mathrm{Fe}$ & Mn & Zn \\
\hline & & \multicolumn{5}{|c|}{ Tipo de composto $\mathrm{x}$ doses } \\
\hline \multirow{3}{*}{$\begin{array}{l}\text { Casca de } \\
\text { Eucalipto }\end{array}$} & 60 & 348 aA & $50 \mathrm{aA}$ & 4688 aA & 981 aA & 297 aA \\
\hline & 120 & 348 aA & $48 \mathrm{aA}$ & 4044 aA & 731 aA & 120 a \\
\hline & 240 & 350 aA & $45 \mathrm{aB}$ & $3865 \mathrm{aB}$ & 520 aA & $344 \mathrm{aB}$ \\
\hline Média & & $349 \mathrm{~B}$ & $48 \mathrm{~B}$ & $4199 \mathrm{~B}$ & $800 \mathrm{~B}$ & $316 \mathrm{~B}$ \\
\hline \multirow{3}{*}{$\begin{array}{l}\text { Serragem de } \\
\text { madeira }\end{array}$} & 60 & 323 aA & $45 \mathrm{aA}$ & 4316 aA & 1111 aA & 276 aA \\
\hline & 120 & 362 aA & 52 aA & 4365 aA & 988 aA & 289 aA \\
\hline & 240 & 364 aA & $57 \mathrm{aB}$ & 5352 aA & 1189 aA & $346 \mathrm{aB}$ \\
\hline Média & & $350 \mathrm{~B}$ & $51 \mathrm{~B}$ & $4677 \mathrm{~B}$ & $1097 \mathrm{AB}$ & $304 \mathrm{~B}$ \\
\hline \multirow{3}{*}{$\begin{array}{l}\text { Palhada de } \\
\text { Feijão }\end{array}$} & 60 & $432 \mathrm{bA}$ & $51 \mathrm{bA}$ & $4533 \mathrm{bA}$ & $1283 \mathrm{bA}$ & $300 \mathrm{bA}$ \\
\hline & 120 & $491 \mathrm{bA}$ & $59 \mathrm{bA}$ & 5605 bA & 1548 bA & $353 \mathrm{bA}$ \\
\hline & 240 & 632 aA & 96 aA & $9252 \mathrm{aA}$ & 1954 aA & 596 aA \\
\hline \multirow[t]{2}{*}{ Média } & & $519 \mathrm{~A}$ & $68 \quad \mathrm{~B}$ & $6463 \mathrm{~A}$ & $1596 \mathrm{~A}$ & $416 \mathrm{~A}$ \\
\hline & & \multicolumn{5}{|c|}{ Solo } \\
\hline$\overline{\mathrm{LE}}$ & & $464 \mathrm{a}$ & $68 \mathrm{a}$ & 6254 a & $1800 \mathrm{a}$ & $453 \mathrm{a}$ \\
\hline \multirow[t]{2}{*}{$\mathrm{AQ}$} & & $349 \mathrm{~b}$ & $44 a$ & 3973 b & $529 \mathrm{~b}$ & $238 \mathrm{~b}$ \\
\hline & & \multicolumn{5}{|c|}{ Testemunha } \\
\hline$\overline{\mathrm{LE}}$ & & 310 & 41 & 5094 & 1390 & 205 \\
\hline $\mathrm{AQ}$ & & 191 & 40 & 5223 & 970 & 240 \\
\hline Média & & 250 & 40 & 5158 & 1180 & 222 \\
\hline$\overline{C V}(\%)$ & & 21 & 25 & 32 & 80 & 31 \\
\hline
\end{tabular}

Letras minúsculas comparam médias das doses dentro de cada composto e médias de solos. Letras maiúsculas comparam médias entre os compostos para uma mesma dose. Médias seguidas das mesmas letras não diferem estatisticamente entre si pelo teste de Tukey à $5 \%$ de probabilidade.

gem de madeira (Tabela 1). As plantas desenvolvidas com composto de palhada de feijão apresentaram coloração verde mais intensa, o que reflete melhor o estado nutricional, principalmente, quanto ao nitrogênio.

O uso de palhada de feijão na maior dose, aos 35 dat (resultados não apresentados) revelou o valor de 33 unidades SPAD, e aos 56 dat revelou 23 unidades SPAD. Portanto houve decréscimo dos teores de clorofila na planta, o que significa que o composto de palhada de feijão não conseguiu manter o mesmo conteúdo nutricional ao longo do ciclo.

As quantidades de macronutrientes na planta de alface em função dos tratamentos, revelaram diferença significativa entre os tipos de compostos orgânicos, sendo que valores estatisticamente superiores foram obtidos com aplicação do composto de palhada de feijão para todos os macronutrientes, exceto o fósforo. Para esse mesmo composto, notou-se também que a quantidade de nutrientes na planta foi diretamente proporcional à dose aplicada.

Houve interação significativa para doses x tipo de composto, sendo que esta ocorreu a partir da dose de $120 \mathrm{~g} \mathrm{vaso}^{-1}$. $\mathrm{Na}$ testemunha, a quantidade de $\mathrm{N}$ planta $^{-1}$ foi de $153 \mathrm{mg}$ (média dos dois solos), valor semelhante ao obtido para doses de 60 gramas dos compostos de casca de eucalipto e serragem, sugerindo que estes compostos não contribuíram para o fornecimento de nitrogênio e também não diminuíram a quantidade de $\mathrm{N}$ disponível para as plantas, isto é, não houve imobilização de nitrogênio, provavelmente, devido à menor relação $\mathrm{C} / \mathrm{N}$ do composto obtido com palhada de feijão.
Na comparação dos tipos de composto $\mathrm{x}$ solos, as plantas apresentaram valores de 242 e $121 \mathrm{mg}$ de $\mathrm{N}_{\text {planta }}{ }^{-1}$ para LE e AQ, respectivamente. No solo AQ esse resultado pode ser relacionado ao baixo conteúdo natural de nutrientes, bem como à menor capacidade de retenção de água.

Para o fósforo, o tratamento com palhada de feijão foi significativamente superior ao de casca de eucalipto e semelhante ao de serragem. Diferentemente do ocorrido para $\mathrm{N}$, não foi observada interação significativa para os tratamentos avaliados, ou seja, foram observadas diferenças significativas na quantidade de $\mathrm{P}$ na planta apenas entre os compostos mas não entre os solos.

A quantidade de $\mathrm{K}$ na planta variou significativamente em função dos tipos de compostos orgânicos, sendo maior no tratamento com palha de feijão. Houve 
interação significativa entre composto $\mathrm{x}$ doses e também entre solo $\mathrm{x}$ doses. Nesse último caso, nota-se que para AQ as quantidades de $\mathrm{K}$ foram significativamente menores apesar de ambos os solos apresentarem inicialmente teores semelhantes de K. Provavelmente, a menor retenção de água no solo $\mathrm{AQ}$ (maior macroporosidade), disponibilizou também menor quantidade de água para a planta e, conseqüentemente, menor desenvolvimento e por ser o potássio absorvido por difusão e fluxo de massa (Malavolta et al. 1997), também menor extração desse nutriente pela planta.

Para $\mathrm{Ca}, \mathrm{Mg}$ e S ocorreram diferenças estatísticas entre os compostos orgânicos utilizados, sendo obtido aumento na quantidade destes nutrientes na planta, com o uso de palhada de feijão. Este aumento foi diretamente proporcional ao incremento na dose do composto. Houve também interação significativa entre as dosagens e os compostos.

Quanto aos micronutrientes, ocorreram diferenças estatísticas entre os compostos, sendo que o de palhada de feijão apresentou sempre valores mais elevados (Tabela 3 ), ocorrendo incrementos significativos com o aumento da dosagem aplicada. Interações entre doses e tipos de compostos ocorreram para a quantidade de $\mathrm{Fe}, \mathrm{Cu}$ e $\mathrm{Zn}$ na planta.

Algumas hipóteses podem ser consideradas para explicar os resultados obtidos. As relações $\mathrm{C} / \mathrm{N}$ entre os compostos são diferentes principalmente se considerarmos casca de eucalipto e serragem de madeira em relação à palhada de feijão. Para esse último composto, com menor relação C/N (10/1), a liberação de nutrientes é mais rápida para as plantas de alface em relação aos outros dois compostos. Esta inferência pode ser reforçada pelo fato que alguns compostos apresentam estruturas de difícil decomposição pela população microbiana do solo, como a celulose e lignina presentes nos compostos de casca de eucalipto e serragem de madeira. Além disso, Inoko (1982) cita que na decomposição de materiais provenientes de madeira, são liberados para o meio resinas, terpenóides e substâncias fenólicas, dentre outros compostos, que podem causar injúrias nas plantas. Ou- tra característica intrínseca do composto que poderia estar influenciando nos resultados é a concentração de nutrientes. Nota-se que a relação $[\mathrm{Ca}+\mathrm{Mg}] / \mathrm{K}$ é bastante elevada para o composto de serragem de madeira em relação aos outros dois compostos, o mesmo ocorrendo para relação $\mathrm{K} / \mathrm{Mg}$ para o composto de casca de eucalipto.

O tipo de composto orgânico pode ter influenciado a retenção de umidade do solo, uma vez que esse efeito é tanto maior quanto mais decomposto está o material (Mays et al., 1973; Hornick, 1988; Tester, 1990). Considerando que o composto de palha de feijão apresentou relação $\mathrm{C} / \mathrm{N}$ mais baixa, possivelmente tenha favorecido a retenção de água em relação aos outros tratamentos.

O composto de palhada de feijão promoveu incremento na biomassa fresca, seca e nas quantidades de macro e micronutrientes extraído pelas plantas de alface, bem como respondeu até a quantidade de $240 \mathrm{~g}$ vaso $^{-1}$, podendo inferir que este composto apresenta-se como melhor fornecedor de nutrientes, o que não foi observado para o composto de casca de eucalipto e serragem de madeira, durante o ciclo da alface (56 dias). Os tratamentos tiveram maior efeito no Latossolo Vermelho Escuro que na Areia Quartzoza.

\section{LITERATURA CITADA}

ALEXANDER, M. Nitrification. In: BARTHOLOMEN, W.V.; CLARK, F.E.; eds. Soil Nitrogen. Madison: American Society of Agronomy, 1965. p.307-343.

ALLISON, F.E. Soil organic matter and its role in crop production. London: Elsevier Scientific Publishing Co., 1973. $637 \mathrm{p}$.

BANZATO, D.A.; KRONKA, S.N. Experimentação agrícola. Jaboticabal: Funep, 1989. 247 p. BRASIL, Ministério da Agricultura. Divisão de Corretivos e Fertilizantes. Inspeção e fiscalização da produção e do comércio de fertilizantes, corretivos, inoculantes, estimulantes ou biofertilizantes destinados à agricultura. Legislação. Portaria n ${ }^{\circ} 84 / 82$. Portaria ${ }^{\circ} 01 / 83$. Brasília, 1983. $88 \mathrm{p}$.

FNP CONSULTORIA \& COMÉRCIO. Anuário Estatístico da Agricultura Brasileira. São Paulo: FNP, 2000. $140 \mathrm{p}$.

GARCIA, L.L.C.; HAAG, H.P.; MINAMI, K.; DECHEN, A.R. Nutrição mineral de hortaliças. XLIX. Concentração e acúmulo de macronutrientes em alface (Lactuca sativa $\mathrm{L}$.) cv. Brasil 48 e Clause's Aurélia. Anais da ESALQ, Piracicaba, v.39, p.455-484, 1982.
HORNICK, S. Use of organic amendments to increase the productivity of sand and gravel spoils: effect on yield and composition of sweet corn. American Journal of Alternative Agriculture, v.3, n.4, p.156-162, 1988.

INOKO, A. The composting of organic materials and associated maturity problems. Food \& fertilizer techonology center. ASPAC, Japan. (Technical Bulletin ${ }^{\circ}$ 71). 1982.

JUAN, T.C.; CHANG, Y.S. Effects of application of compost and manure on crop growth. Nitrogen mineralization and nitrogen uptake under rice-corn rotation. Soil and Fertilizers in Taiwan. n.1992, p.18-39, 1992.

KATAYAMA, M. Nutrição e Adubação de alface, chicória e almeirão. In: FERREIRA, M.E; CASTELLANE, P.D.; CRUZ, M.C.P. eds. Nutrição e Adubação de Hortaliças. Piracicaba: Associação Brasileira para Pesquisa da Potassa e do Fosfato, 1993. p.141-148.

KIEHL, E.J. Fertilizantes orgânicos. São Paulo: Agronômica Ceres, 1985. 492 p.

KIEHL, E.J. Manual de compostagem maturação e qualidade do composto. Piracicaba, 1998. $171 \mathrm{p}$.

KOGA, P.S.; SENO, S. Efeitos de diferentes materiais orgânicos em cultivos consecutivos de alface e pepino, sob condições de ambiente protegido. In: CONGRESSO BRASILEIRO DE OLERICULTURA, 37, 1997, Manaus. Resumos.. Manaus: Horticultura Brasileira, Brasília, v.15, 1997. s/p.

LANARV Laboratório Nacional de Referência Vegetal. Análise de corretivos, fertilizantes $e$ inoculantes - métodos oficiais. Brasília, Secretaria Nacional de Defesa Agropecuária - Ministério de Agricultura, 1988. 104 p.

MALAVOLTA, E.; VITTI, G.C.; OLIVEIRA, S.A. Avaliação do estado nutricional de plantas: princípios e aplicações. Piracicaba: POTAFOS, 1997. 319 p.

MAYS, D.A.; TERMAN, G.L.; DUGGAN, J.C. Municipal compost: effects on crop yield and soil properties. Journal of environmental quality, v.2, n.1, p.89-92, 1973.

NAKAGAWA, J.; BÜLL, L.T.; PROCHNOW, L.I.; VILLAS BOAS, R.L. Efeitos de compostos orgânicos na cultura do alface (Lactuca sativa L.). Série I. Cientifica, São Paulo, v.20, n.1, p.173-180, 1992. NAKAGAWA, J.; KAMITSUJI, M.K.; PIERI, J.C.; VILLAS BÔAS, R.L. Efeitos do bagaço, decomposto por ação de biofertilizante, na cultura da alface. Científica, São Paulo, v.21, n.1, p.169177, 1993.

PEIXOTO, R.T.G. Composto orgânico: aplicações, benefícios e restrições de uso. Horticultura Brasileira, Brasília, v.18 suplemento, p.56-64. 2000.

PEREIRA, N.N.C.; FERNANDES, M.S.; ALMEIDA, D.L. Adubação nitrogenada na cultura da alface, fontes de nitrogênio e inibidor de nitrificação. Pesquisa Agropecuária Brasileira, Brasília, v.24, n.6. p.647-654, 1989.

RAIJ, B.V; CANTARELLA, H.; QUAGGIO, A.J.; FURLANI, A.M.C. Recomendação de adubação e calagem para o estado de São Paulo. Campinas: IAC, 1997. 285 p. (Boletim técnico no 100) RICCI, M.S.F.; CASALI, V.W.D.; CARDOSO, A.A.; RUIZ, H.A. Teores de nutrientes em duas cultivares de alface (Lactuca sativa L.) adubadas com composto orgânico. In: REUNIÃO BRASILEIRA DE FERTILIDADE DO SOLO E NUTRIÇÃO DE PLANTAS, 21, 1994, Petrolina, Resumos... Petrolina: EMBRAPA-CPATSA/SBCS, p.326-327, 1994. 
SCHNEIDER, L. Rendimento e qualidade de alface em função de adubação nitrogenada orgânica e mineral. Porto Alegre: UFRGS, 1983. 69 p. (Tese mestrado)

SENESI, N. Composted materials as organic fertilizers. The science of the total environment, 81/82, 1989. p.521-542.

SWIFT, M.J.; WOOMER, P. Organic matter and the sustainability of agricultural sistems: definitions and measurement. In: MULUNGOY, K.; MERCKX, R. (Eds.). Soil organic matter dynamics and sustainability of tropical agriculture. Leuven: Wilei-Sayce co. 1993. p.3-18.
TESTER, C.F. Organic amendment effects on physical and chemical properties of a sand soil. Soil Science Society of America Journal, v.54, p.827-831, 1990.

VIDIGAL, S.M.; SEDIYAMA, M.A.N.; GARCIA, N.C.P. MATOS, A.T. Compostos orgânicos contendo dejeto de suíno como fonte de $\mathrm{N}$ : Efeito residual da adubação orgânica no estado nutricional de plantas de alface (Lactuca sativa L.). In: CONGRESSO BRASILEIRO DE CIÊNCIA DO SOLO, 25, 1995, Viçosa. Resumos Expandidos... Viçosa: UFV, 1995, v.2, p.672-674.
VIDIGAL， S.M.; SEDIYAMA， M.A.N.; GARCIA, N.C.P.; MATOS, A.T. Produção de alface cultivada com diferentes compostos orgânicos e dejetos suínos. Horticultura Brasileira Brasília, v.15, n.1. p.35-39. 1997. 